\title{
Sight distance restriction on highways' horizontal curves: insights and sensitivity analysis
}

\author{
Shy Bassan ${ }^{1}$
}

Received: 6 November 2015 / Accepted: 14 July 2016 / Published online: 3 August 2016

(C) The Author(s) 2016. This article is published with open access at SpringerLink.com

\begin{abstract}
Introduction The study focuses on sight distance restrictions on horizontal curves in highway design. Barriers along open highways and walls on tunnels may restrict the available sight distance in the design of horizontal curves. The study aims to finalize a desirable horizontal radius by examining the equilibrium requirement of the centrifugal force vs. horizontal sight distance constraints.

Methods The study examines these restrictions for the conventional case when the stopping sight distance lies within the length of the horizontal curve (case 1) and when the stopping sight distance lies outside the length of the horizontal curve (case 2). Also included in this study is a sensitivity analysis when the stopping sight distance is longer than the length of horizontal curve (case 2), based on the ratio between them. Results For the conventional case (case 1) the minimum horizontal radius that is based on the equilibrium of centrifugal force, is too small for the requirements of stopping sight distance when there are obstructions along the road that intrude on the line of sight. Sensitivity analysis results for case 2 show that the gap between the available horizontal stopping sight distance (for the minimum horizontal radius) vs. the design (demanded) stopping sight distance values and between the minimum horizontal radius vs. the desirable radius can be totally resolved when the ratio between stopping sight distance and the length of horizontal curve equals to 4.5 (for
\end{abstract}

This paper is dedicated to my father, Shabtay Bassan, who passed away on April 18th 2016.

Shy Bassan

shy-b@amymetom-ta.co.il; bassans@netvision.net.il

1 Amy Metom Engineers \& Consultants, Ltd., 55A Yigal Alon St, 67891 Tel Aviv, Israel horizontal sightline offset of $4.8 \mathrm{~m}$, i.e. shoulder width of $3.0 \mathrm{~m}$ plus half lane width of $1.8 \mathrm{~m}$ ).

Conclusions Practically, the resulted conditions of the ratio between stopping sight distance and the length of horizontal curve are not feasible in horizontal curve design especially when the horizontal sightline offset equals to $3.0 \mathrm{~m}$. When the limitations of horizontal stopping sight distance are valid and the obstruction height is higher than the maximum, the highway engineer might consider a tradeoff by increasing the horizontal curve radius as well as adjusting the design to case 2 .

Keywords Highway · Sight distance $\cdot$ Horizontal curve · Equilibrium $\cdot$ Restriction

\section{Introduction}

A major purpose in highway geometric design is to ensure that the driver is able to see any possible road hazard in sufficient time to take action and avoid an accident. Stopping sight distance (SSD) is the most important of the sight-distance considerations since sufficient SSD is required at any point along the roadway.

\subsection{Stopping sight distance (SSD)}

SSD is the distance that the driver must be able to see ahead along the roadway while traveling at or near the design speed and to safely stop before reaching an object whether stationary or not. SSD can be limited by both horizontal and vertical curves. The fact that it impacts the design radius of both curves makes SSD so fundamental in the highway design process. This study focuses on sight distance restriction on horizontal curves.

The stopping sight distance has two components: (1) the distance traveled during the driver's reaction time; (2) the 
distance traveled during braking. This distance, assuming a level road surface, can be determined by the following formula:

$S S D=\frac{t_{R}}{3.6} \cdot V_{d}+\frac{V_{d}^{2}}{2 \cdot 3.6^{2} \cdot d}$

where:

SSD Minimum stopping sight distance (m)

$\mathrm{V}_{\mathrm{d}} \quad$ Design speed $(\mathrm{km} / \mathrm{h})$

d Deceleration of passenger cars $\left(\mathrm{m} / \mathrm{s}^{2}\right)$, equivalent to the longitudinal friction coefficient (f) multiplied by the acceleration of gravity $(\mathrm{g})$

g Nominal gravitational acceleration of an object in a vacuum near the surface of the earth $\left(\mathrm{g}=9.81 \mathrm{~m} / \mathrm{s}^{2}\right)$

$t_{R} \quad$ Perception reaction time (s), usually $2.5 \mathrm{~s}$ (AASHTO 2011).

The formula assumes level terrain. Ascending grade decreases the SSD, and descending grade increases the SSD.

The green book $[1,2]$ recommends on $3.4 \mathrm{~m} / \mathrm{s}^{2}$ as a reasonable deceleration rate for obtaining the stopping sight distance and it no longer provides the tangent friction coefficient design values. Most vehicles are able to brake in this rate at least, under wet pavement conditions. The tangent friction coefficient in wet pavement surfaces and the modern vehicle braking capabilities typically enable larger equivalent friction coefficients than this deceleration rate.

\subsection{Horizontal curve design: equilibrium concept}

A proper design of highway horizontal curves should strive for the maximum curvature or the minimum radius just under the most critical conditions. It is, therefore, necessary to establish an appropriate relationship among the design speed, the horizontal curve radius, and the superelevation based on circular motion law of mechanics. The minimum radius or the maximum curvature has a limiting value for a given design speed as determined according to the maximum rate of superelevation $\left(\mathrm{e}_{\max }\right)$ and the maximum side-friction coefficient $\left(\mathrm{f}_{\mathrm{Rmax}}\right)$ :

$R_{\min }=\frac{V_{d}^{2}}{3.6^{2} \cdot\left(g \cdot e_{\max }+g \cdot f_{R \max }\right)}=\frac{V_{d}^{2}}{127 \cdot\left(e_{\max }+f_{R \max }\right)}$

where:

$\mathrm{R}_{\min } \quad$ minimum radius of horizontal curve (m)

$\mathrm{V}_{\mathrm{d}} \quad$ design speed $(\mathrm{km} / \mathrm{h})$

$\mathrm{g} \cdot \mathrm{e}_{\max }=\mathrm{a}_{\mathrm{e}} \quad$ superelevation acceleration

$\mathrm{g} \cdot \mathrm{f}_{\mathrm{Rmax}}=\mathrm{a}_{\mathrm{fr}}$ friction lateral acceleration

$a_{c}=a_{e}+a_{f r}$ centrifugal acceleration

127 conversion factor, taking acceleration of gravity as $\mathrm{g}=9.81 \mathrm{~m} / \mathrm{s}^{2}$

The use of a smaller radius (sharper curvature) than the minimum radius for the prevailing design speed might necessitate a non-practical superelevation or side-friction coefficient beyond the safety limits. Table 1 presents the minimum horizontal radii design values according to AASHTO [2] assuming a maximum superelevation of $8 \%$. This maximum superelevation is assumed for the analysis conducted in this study but can be different, based on the highway authority design policy.

\section{Stopping sight distance (SSD) restriction along horizontal curves and vertical curves: literature review}

The literature incorporates several research studies that discuss the provision of horizontal sight distance around safety barriers and other structures (e.g. retaining walls) either when it is possible to see over them or not (Fig. 1). Such studies (e.g. [3-7]) discuss this sight distance issue along open roadways.

Arndt et al. [3] proposed the implementation of dry longitudinal friction coefficient of 0.61 , utilizing high object height (e.g. $0.80 \mathrm{~m}$ ), and reducing the design speed values based on speed prediction models, assuming that drives are prepared to slow prior to horizontal curves. They also proposed the perception reaction time value of $1.5 \mathrm{~s}$ of alert driving due to road environment and driving expectancy [8]. These less conservative criteria have been suggested to result in a lower but reasonable design value of stopping sight distance.

Still these criteria have been used in a case study of provision of sight distance around roadside safety barriers on freeways and interchanges by using a particular operating speed $80 \mathrm{~km} / \mathrm{h}$.

\subsection{D models combining horizontal and vertical alignments}

Sarhan and Hassan [4] analyzed available stopping sight distance (SSD) on horizontal curves with roadside or median barriers in 3 Dimension (3D) combined alignments by using finite element technique software. Their analysis confirmed the dependency between the available SSD on horizontal curves (due to road barriers) and overlapping vertical alignment. They found that the available SSD increases as the overlapping crest vertical curve becomes flatter or as the overlapping sag vertical curve becomes sharper. The design aids presented in this research, which include available SSD, the horizontal sightline offset (HSO), and different alternatives of overlapping vertical curves, considered open roads SSD criteria where most range of horizontal sight line offset (HSO) is not practical for implementation in a bounded cross section or derives uneconomical wide shoulders which can mislead the drivers by using them as another travel lane or a parking lay-bay. Also, the design speed parameter was not 
Table 1 Minimum horizontal radii $(\mathrm{m})$ for emax $=0.08$ [2]

\begin{tabular}{|c|c|c|c|c|c|c|c|}
\hline \multirow[t]{2}{*}{ Parameter } & \multicolumn{7}{|c|}{ Design Speed (km/h) } \\
\hline & 60 & 70 & 80 & 90 & 100 & 110 & 120 \\
\hline $\begin{array}{l}\mathrm{e}_{\max } \\
\text { (max superelevation) }\end{array}$ & 0.08 & 0.08 & 0.08 & 0.08 & 0.08 & 0.08 & 0.08 \\
\hline $\begin{array}{l}\mathrm{f}_{\mathrm{Rmax}} \\
\text { max side friction }\end{array}$ & 0.17 & 0.15 & 0.14 & 0.13 & 0.12 & 0.11 & 0.09 \\
\hline $\begin{array}{l}\mathrm{R}_{\min } \\
\text { min horizontal radius }(\mathrm{m})\end{array}$ & 113 & 168 & 229 & 304 & 394 & 501 & 667 \\
\hline
\end{tabular}

included in these charts where the constraint of non-available horizontal sightline is not always accomplished.

Additional studies aimed to evaluate and optimize the actual sight distance in real driving conditions by 3D models. Nehate and Rys [9] examined the intersection of sightline with the elements representing the road surface by an algorithm which combines horizontal and vertical alignment and automatically calculate sight-distance profile along any given highway for which Global Positioning System's (GPS's) data are available. Results of actual data have shown the ability to identify sight-distance restrictions. Similarly, Kim and Lovell [10] used computational geometry and thin plate Spline interpolation to represent the road surface and eventually determine the maximum available sight distance.

Castro et al. [11] implemented a procedure supported by Geographic Information Systems (GIS) in order to determine highway distances visible to the driver in a two-lane highway section. The GIS advantage in highway sight distance analysis is using data sources that besides the terrain include obstacles like trees or buildings that could reduce the driver sight distance. This procedure can perform highway sight distance analysis of existing highways where highway design information (tangents, horizontal and vertical curves) is not available or is not the latest (e.g. in many already built highways). Castro et al. [11] showed that sight distances obtained by GIS approach and the classic highway design approach are statistically the same.

Jha et al. [12] proposed a 3-D design methodology which is capable of "efficiently measuring the sight distance for different superelevation, day and nighttime conditions, and obstructions".

The methodology which utilizes triangulation techniques (Digital Terrain Model - DTM) consists of three stages: development of (a) the road surface, (b) virtual field-of-view surface, and (c) virtual line of sight-plane. Moreno et al. [6] maximized the available stopping sight distance (SSD) at crest vertical curves overlapped with horizontal curves in two lane highways. They used a finite element method algorithm to generate an SSD profile. The available SSD profile indicated the available SSD of each evaluated position of the driver. The

Fig. 1 Limited sight distance on horizontal curves with median safety barrier along a left curve in multilane highways (restructured from [7])
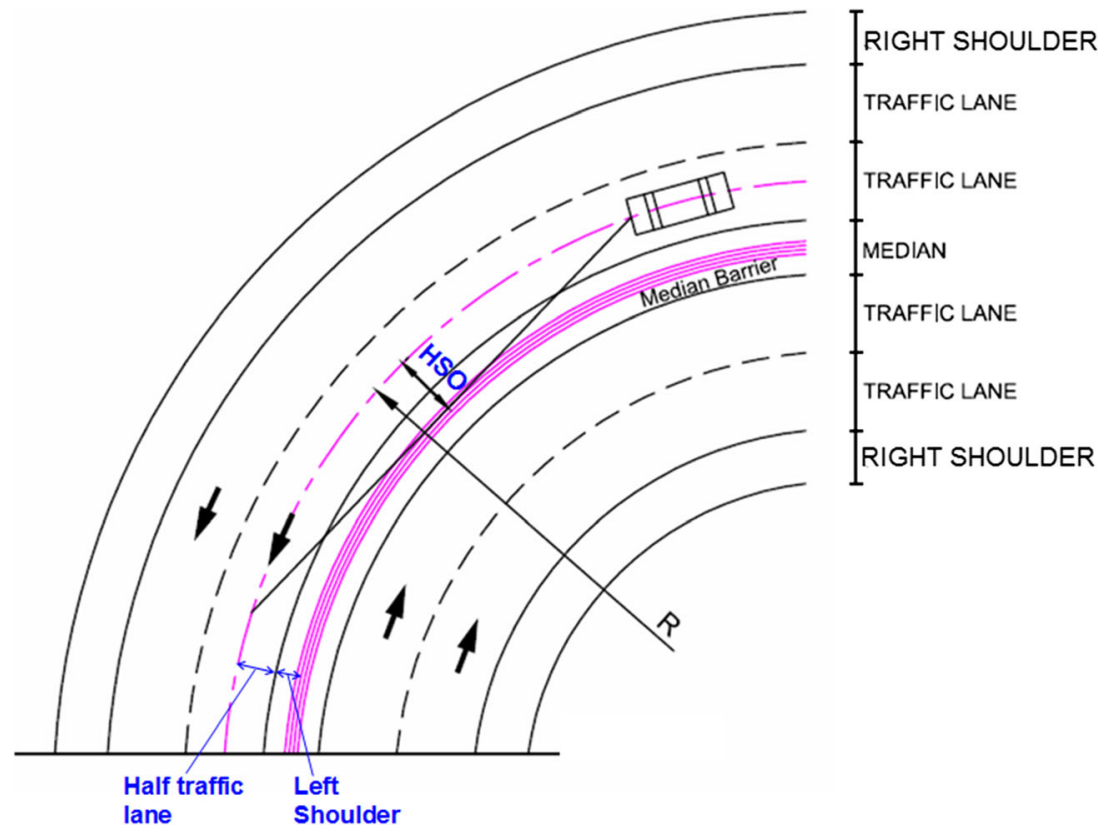
resulted available SSD could finalize certain alignment zones where vertical and horizontal curve could be improved if the minimum available SSD was lower than required among these curves. This study concluded that the vertical curve curvature in meters $\left(\mathrm{K}_{\mathrm{v}}=\mathrm{L}_{\mathrm{v}} / \mathrm{A}=\mathrm{R}_{\mathrm{v}} / 100\right.$, i.e. the horizontal distance in meters needed to make a $1 \%$ change in gradient, where: $\mathrm{L}$ is the horizontal length of vertical curve in meters, $A$ is the algebraic difference of grade lines in percents, $R_{v}$ is the vertical curve radius in meters), and the available horizontal radius $\left(R_{h}\right)$ affect the available SSD. The optimal proportion of $K_{v} / R_{h}\left(K_{v}\right.$ and $R_{h}$ were previously defined) which maximizes the available SSD is generally ranged between 0.05 to 0.15 . The study also revealed a negligible impact of the offset between horizontal and vertical curves on available SSD. Additionally, the layout visibility got restricted to the point where the superelevation changed its sign [6].

Mavomartis et al. [5, 13] proposed an "accurate SSD control method" which relates the 3D alignment of the roadway (horizontal and vertical) to the dynamics of vehicle path along the roadway based on the difference between the available SSD and the "demanded" SSD. The method was applied to left turn horizontal curve divided highway. The SSD adequacy was evaluated by equalizing the available SSD and the demanded SSD and by identifying the zones where the sightline is obstructed by the median width. Their results have shown that by increasing the horizontal radius, inside the vertical curve transition area, the restricting area due to object height and blocked driver sightline (insufficient HSO) increases up to a certain point. As the horizontal radii increase more "the blocked sightlines decreases in advance of the object height amendment requirement". This research finally suggested that by increasing the object height ( i.e. vehicle tail lights) to $1.08 \mathrm{~m}$, the design consistency, and driver expectations can be satisfied by avoiding non-uniformed posted speed limits and uneconomical lateral road widening. Ismail and Sayed [14] presented a finite element approach of a 3D algorithm that calculates ASD for integrated vertical and horizontal alignments. This algorithm parameterizes horizontal elements such as pavement edge, median edge, and side slope relative to the centerline. Its final step similarly to other 3D methodologies is searching for the furthest object location that connects the driver location with an unobstructed sightline. The algorithm examined extreme cases of vertical and horizontal curvatures in order to validate them against available $2 \mathrm{D}$ models. The resulted 3D ASD was closed to the shortest of the 2D ASD sight distances (horizontal ASD, i.e. HASD and vertical ASD i.e. VASD). The 3D ASD resulted smaller than the critical 2D ASD if the 2D difference is positive (VASD > HASD). This case signified the necessity of 3D analysis.

\subsection{Reliability analysis of sight distance in horizontal curves}

Hussein and Sayed [7] applied reliability analysis (stochastic approach) to take into consideration uncertainty associated with geometric design parameters. They calibrated design charts for Horizontal Sightline Offset- HSO, or in other words: the middle ordinate $-\mathrm{M}$, at different probabilities of non-compliance (Pnc) levels. The HSO which is presented in Fig. 1 is the distance between the edge of median barriers and the centerline of the left traffic lane.

In highway geometric design the use of Pnc characterizes the probability that the design does not meet the standard design requirement. Hussein and Sayed used a limit state function which is the difference between ASD (available stopping sight distance) and the demanded stopping sight distance (SSD). The Pnc was generated from this function. SSD is presented in Eq. 1. ASD is the accurate horizontal sight distance formula assuming SSD is shorter than the horizontal curve length (L). Its approximate form is documented in the next section which is the background for the major objective of the current study to conduct a sensitivity analysis of R and HSO for SSD $<$ L and $\mathrm{SSD}>\mathrm{L}$.

The preferred target Pnc is the road designer's choice based on the design policy.

The calibration of horizontal radius and HSO for different Pnc's showed that the current design guides are conservative especially at sharp radii and high design speed [7]. It appears that these results are somehow subjective because increasing the risk (i.e. increasing the target Pnc) can be performed by deterministic modifications such as reducing the perception reaction time (PRT) or increasing the friction coefficient (Eq. 1) based on the prevailing traffic and pavement conditions and specific driving behavior characteristics.

The reliability analysis approach was also implemented in other studies such as Ismail and Sayed [15] and Ibrahim et al. [16] in order to select a suitable combination of cross section elements with restricted sight distance to result in reduced collisions and acceptable risk levels.

\section{Horizontal sightline offset (Hso): basic methodology}

An approximate calculation of the minimum horizontal sightline offset (HSO) or the lateral clearance required between the centerline of the inside lane and a potential obstruction along the horizontal curve can be performed as a function of the sight distance, and the radius of the horizontal curve $\left(\mathrm{R}_{\mathrm{HSD}}\right)$. 


\subsection{Horizontal sightline offset (HSO) for SSD $\leq \mathrm{L}$, case 1}

Figure 2 presents a typical sketch of the horizontal sight distance (SD) calculation. It is assumed that the sight distance lies within the length of the horizontal curve (L) and SD approximates to a straight line.

Using the right angle rule for triangle A (Fig. 1 right):

$\mathrm{R}^{2}=\mathrm{x}^{2}+(\mathrm{R}-\mathrm{HSO})^{2}$

Similarly for triangle B (Fig. 2 right) we get:

$$
((\mathrm{SD}) / 2)^{2}=\mathrm{x}^{2}+(\mathrm{HSO})^{2}
$$

Combining Eqs. 3 and 4 and isolating the joint side of triangles $\mathrm{A}$ and $\mathrm{B}$ result in Eq. 5:

$((\mathrm{SD}) / 2)^{2}-(\mathrm{HSO})^{2}=\mathrm{R}^{2}-(\mathrm{R}-\mathrm{HSO})^{2}$

After further arrangements, we get the approximate relationship between HSO, SSD, and the horizontal curve radius $\left(\mathrm{R}_{\mathrm{HSD}}\right)$, as shown in Eq. 6.

$(\mathrm{SD}) / 2)^{2}=+2 \cdot \mathrm{R} \cdot \mathrm{HSO}$

$\mathrm{HSO}=(\mathrm{SSD})^{2} /\left(8 \cdot \mathrm{R}_{\mathrm{HSD}}\right)$ for $\mathrm{SSD} \leq \mathrm{L}$

Or

$S S D=\sqrt{8 \cdot H S O \cdot R_{H S D}} \quad$ for $\mathrm{SSD} \leq \mathrm{L}$

HSO free horizontal sightline offset between the middle of sightline and the centerline of the inside lane $(\mathrm{m})$.

$\mathrm{R}_{\mathrm{HSD}}$ the horizontal curve radius along the centerline of inside lane (m), written as $\mathrm{R}$ in Eqs. 3-5 and Fig. 2.

SSD stopping sight distance along the sightline (m), written as SD in Eqs. 4-5 and Fig. 2.

\subsection{Horizontal sightline offset (HSO) for SSD $>$ L, case 2}

When the sight distance lies outside the length of the horizontal curve (L) the analysis is slightly different. In this case, assuming two symmetrical tangent edges outside the horizontal curve, we can obtain the relationship between HSO, SSD, the horizontal curve radius $\left(\mathrm{R}_{\mathrm{HSD}}\right)$, and the length of the horizontal curve $(\mathrm{L})$.

Figure 3 presents a typical sketch of the horizontal sight distance (SD) which is larger than the horizontal curve length $(\mathrm{SD}>\mathrm{L})$
By using the right angle rule for triangle ACK (Fig. 2) we get:

$(\mathrm{SSD} / 2)^{2}=\mathrm{x}^{2}+(\mathrm{HSO})^{2}$

By using the right angle rule for triangle AKO (Fig. 3) we get:

$\mathrm{x}^{2}=\mathrm{d}^{2}-(\mathrm{R}-\mathrm{HSO})^{2}$

By using the right angle rule for the symmetrical triangles $\mathrm{ADO}$ or EBO (Fig. 3) we get:

$\mathrm{d}^{2}=((\mathrm{SSD}-\mathrm{L}) / 2)^{2}+(\mathrm{R})^{2}$

After further algebraic arrangements the resulted relationship between HSO, SSD, the horizontal curve radius $\left(\mathrm{R}_{\mathrm{HSD}}\right)$, and the length of horizontal curve (L) is as follows:

$H S O=\frac{L \cdot(2 S-L)}{8 \cdot R_{H S D}} \quad$ for $\mathrm{SSD}>\mathrm{L}$

$\mathrm{Or}$

$S S D=\frac{(H S O) \cdot 4 R_{H S D}}{L}+\frac{L}{2} \quad$ for $\mathrm{SSD}>\mathrm{L}$

Further detail regarding sight distance on horizontal curves including: exact calculations of horizontal sightline offset (HSO), comparison between exact formulas and approximate formulas of $\mathrm{HSO}$, and variation of sight distance according to the location of observer (driver) and object height along the horizontal curve, can be found in Olson et al. [17].

\section{Sight distance restriction along the horizontal curve: insights}

The sight along the inner side of the horizontal curve can be sometimes restricted by downhill excavations, retaining walls, structures, and other obstacles. On divided highways (multilane highways, freeways, etc) the driver sightline while driving along the left-hand side (LHS) horizontal curve is generally restricted by median safety barrier. The median safety barrier is usually closer to the left lane comparing to obstructions located beyond the right shoulder (typically safety barrier). The sightline problem is three dimensional and therefore, it is important to determine the height of its two edges (driver eye height and object height) by the type of sight distance considered. Additionally, the interaction between horizontal and vertical geometry parameters (especially vertical and horizontal curves, presented in section 2) are critical in addressing the available SSD.

The critical (maximum) value of lateral clearance (horizontal sightline offset, HSO) is typically determined in the middle 

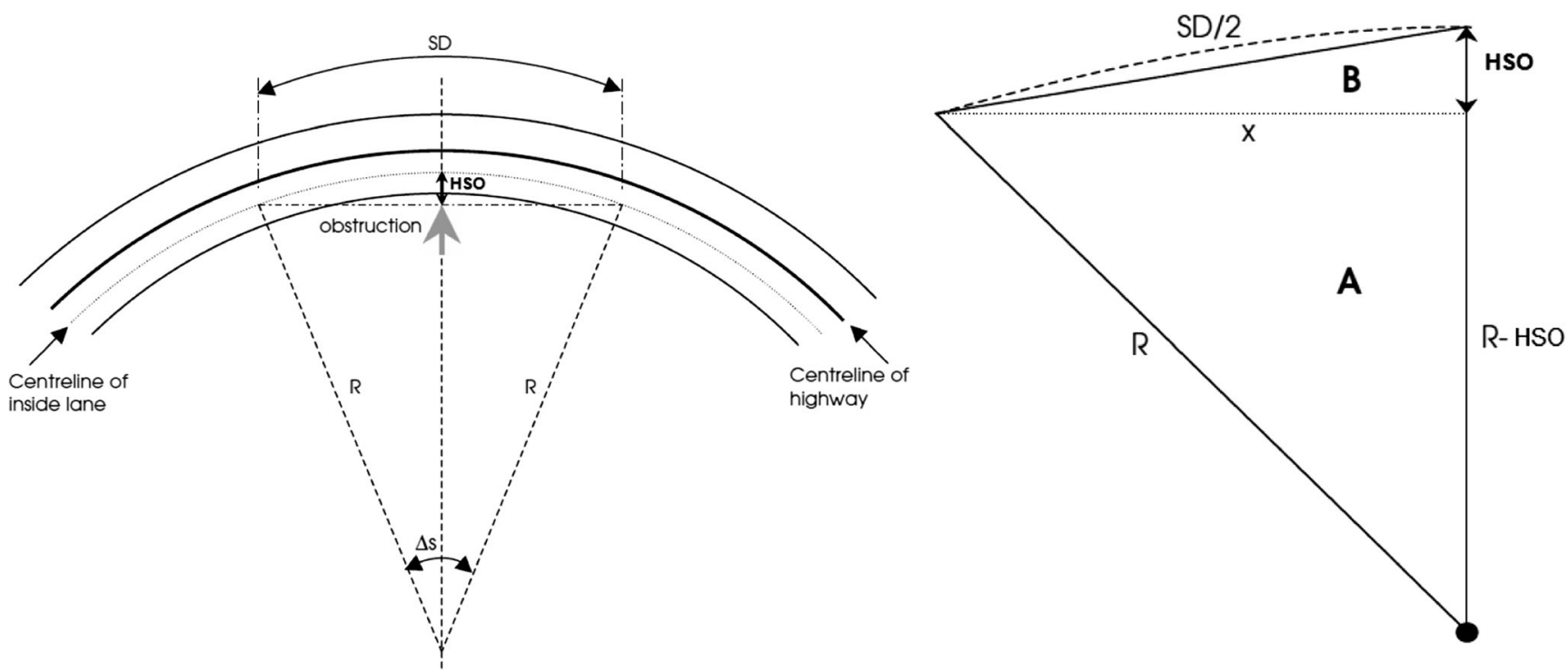

Fig. 2 Horizontal curve SD geometric configuration $(\mathrm{SD} \leq \mathrm{L})$

of sightline (e.g. between points 6 and $6^{\prime}$ in Fig. 4). Hence, this point fits the average height value of two sightline edges' heights. Typical average height values for several sight distance types are presented in Table 2. These averages correspond to the maximum obstruction height to ensure sightline while driving along a horizontal curve. The decision SD and passing SD maximum obstruction height values were supplemented to Table 2 in order to cover the aspect of horizontal curve sightline of different SD types, even though this study focuses on horizontal Stopping Sight Distance sensitivity analysis.

Every point along the inner side of the horizontal curve (and beyond) along the sight envelope (Fig. 4) should not incorporate an obstacle which prohibits the line of sight. If such an obstacle exists (typically, a

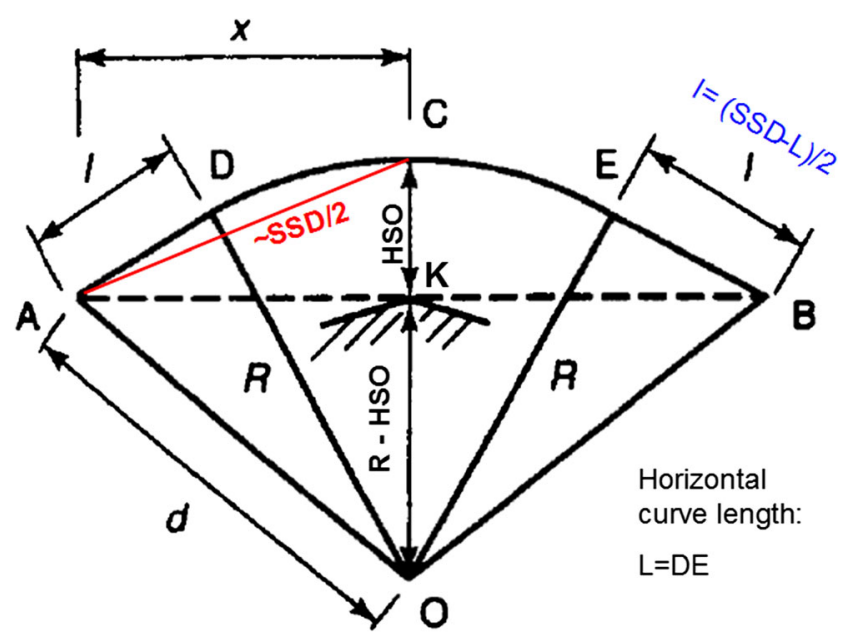

Fig. 3 Horizontal curve SD geometric configuration (SD > L) safety barrier), its height should not exceed the critical obstruction's height presented in Table 2. When the vertical alignment includes a tangent gradient, a profile sketch might be useful.

If the horizontal curve radius does not conform sight distance requirement for a specific design speed due to a local or continuous obstruction (vegetation, downhill excavation, retaining wall, and safety barrier along the median or beyond the right shoulder) whose height exceed the critical obstruction height, the highway engineer might consider increasing the horizontal radius or widening the shoulder without decreasing the design speed.

Barriers along open highways and walls on tunnels may restrict the available sight distance in the design of horizontal curves. The minimum radius that is based on the equilibrium of the centrifugal force (Eq. 2), is too small for the requirements of stopping sight distance when there are obstructions along the road (especially the median barrier on open roadways) that intrude on the line of sight. The limitation of stopping sight distance, which is documented in other references (e.g. [3, $5,8,13])$ could arise as follows:

(1) On two-lane highways, the inside barrier could restrict sight distance in the right-bound curve. The horizontal sightline offset (HSO) could be no more

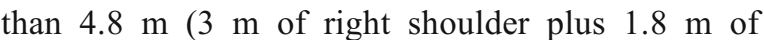
the distance between the centerline of the right lane and its right edge).

(2) On four (or six)-lane divided highways, the median barrier could restrict sight distance in the left-bound curve. The HSO could be no more than $4.8 \mathrm{~m}(3 \mathrm{~m}$ 
Fig. 4 Sight envelope along the horizontal curve

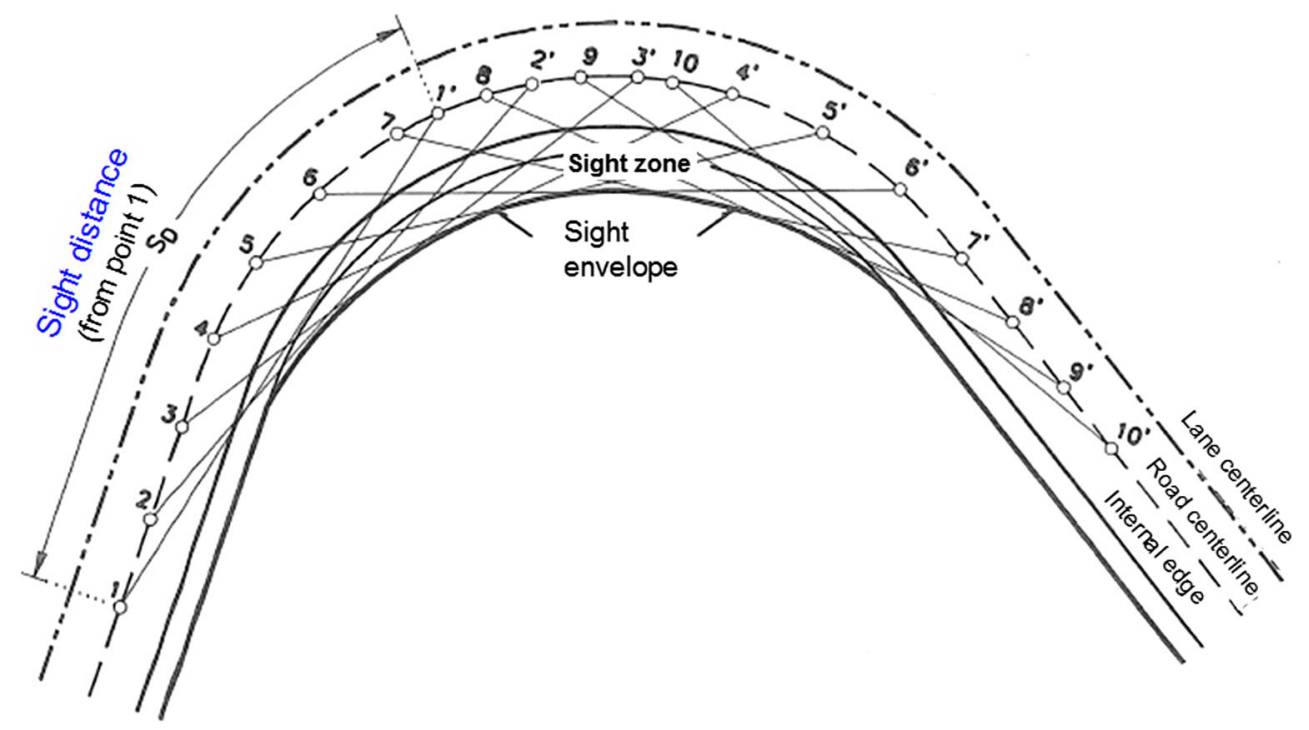

of median/left shoulder width plus $1.8 \mathrm{~m}$ of the distance between the centerline of the left lane and its left edge). A typical cross section of six lanes divided highway is presented in Fig. 5. This cross section incorporates left shoulders of $3.0 \mathrm{~m}$.

The concept of calculating the HSO (including conventional shoulder width of $3.0 \mathrm{~m}$ or narrower and the distance between the lane centerline and its edge) is documented in AASHTO [2] and in Austroads [8]. A typical graphical presentation of HSO on horizontal curves with median safety barrier in multilane highways is presented in Fig. 1.

The HSO could be even smaller (i.e. $3.0 \mathrm{~m}$ ) if the median shoulder is reduced to $1.2 \mathrm{~m}$ (AASHTO [2], sub-section 3.3.12 pp. 3-110).
The outside (median) barrier restriction on multilane divided highways is similar to two-lane highways ( $\mathrm{HSO}=4.8 \mathrm{~m}$ ); however, since design speed is usually higher, the stopping sight distance is even more restricted. This insight is more obvious in road tunnels, where continuous walls run along the sides.

Table 3 presents examples of SSD restrictions on a horizontal curve, based on AASHTO [2] when SSD $<$ L (Eq. 6, Eq. 6a). Figures 6 and 7 show the restricted $\mathrm{SSD}$ line $\left(\mathrm{AB}_{\text {Available }}\right)$ for two-lane highways and six-lane divided highways, assuming $\mathrm{HSO}=4.8 \mathrm{~m}$ and $\mathrm{Rmin}=229 \mathrm{~m}, \mathrm{Rmin}=501 \mathrm{~m}$ (for $\mathrm{V}_{\mathrm{d}}=80 \mathrm{~km} / \mathrm{h}$, and $\mathrm{V}_{\mathrm{d}}=110 \mathrm{~km} / \mathrm{h}$ ) correspondingly.

Table 3 and Figs. 6, 7 emphasize the differences between the available horizontal SSD (for $\mathrm{R}=\mathrm{Rmin}$ ) vs. the design SSD values, and between Rmin (equilibrium concept) and the desirable horizontal radius (based on SSD design values). These differences increase as the design speed increases.
Table 2 Maximum obstruction heights for a clear sightline in horizontal curves

\begin{tabular}{ll}
\hline $\begin{array}{l}\text { Sight Distance (SD) } \\
\text { Type }\end{array}$ & $\begin{array}{l}\text { Maximum Obstruction Height for Horizontal Curve Sightline }\left(^{*}\right), \text { in } \\
\text { meters }\end{array}$ \\
\hline $\begin{array}{l}\text { Stopping SD (undivided highway) } \\
\text { Stopping SD (two-way (divided) }\end{array}$ & $\begin{array}{l}(1.05+0.15) / 2=\mathbf{0 . 6 0} \mathrm{m} \\
\quad \text { highway }\end{array}$ \\
$\begin{array}{l}\text { Decision SD } \\
\text { Passing SD }\end{array}$ & $(1.05+0.60) / 2=0.825 \sim \mathbf{0 . 8 0} \mathbf{~ m}$ (rounding down) \\
\hline
\end{tabular}

*Based on passenger car driver eye height of $1.05 \mathrm{~m}$, object height of $0.60 \mathrm{~m}$ for multilane highways, object height of $0.15 \mathrm{~m}$ for two-lane highways, and portion of the vehicle height that needs to be visible for another driver to recognize a vehicle: $1.05 \mathrm{~m}$

**The passenger car driver eye height and the object height for passing sight distance $(1.05 \mathrm{~m})$ were adopted from Israel Highway Design Guidelines [18]. These values are similar to the values proposed by AASHTO 2011 green book values $(1.08 \mathrm{~m})$

***The SSD object height proposed value for two lane highways $(0.15 \mathrm{~m})$ is different from AASHTO (2011) assuming that in lower design speeds drivers are still able to see an object shorter than $0.6 \mathrm{~m}$ [18] 


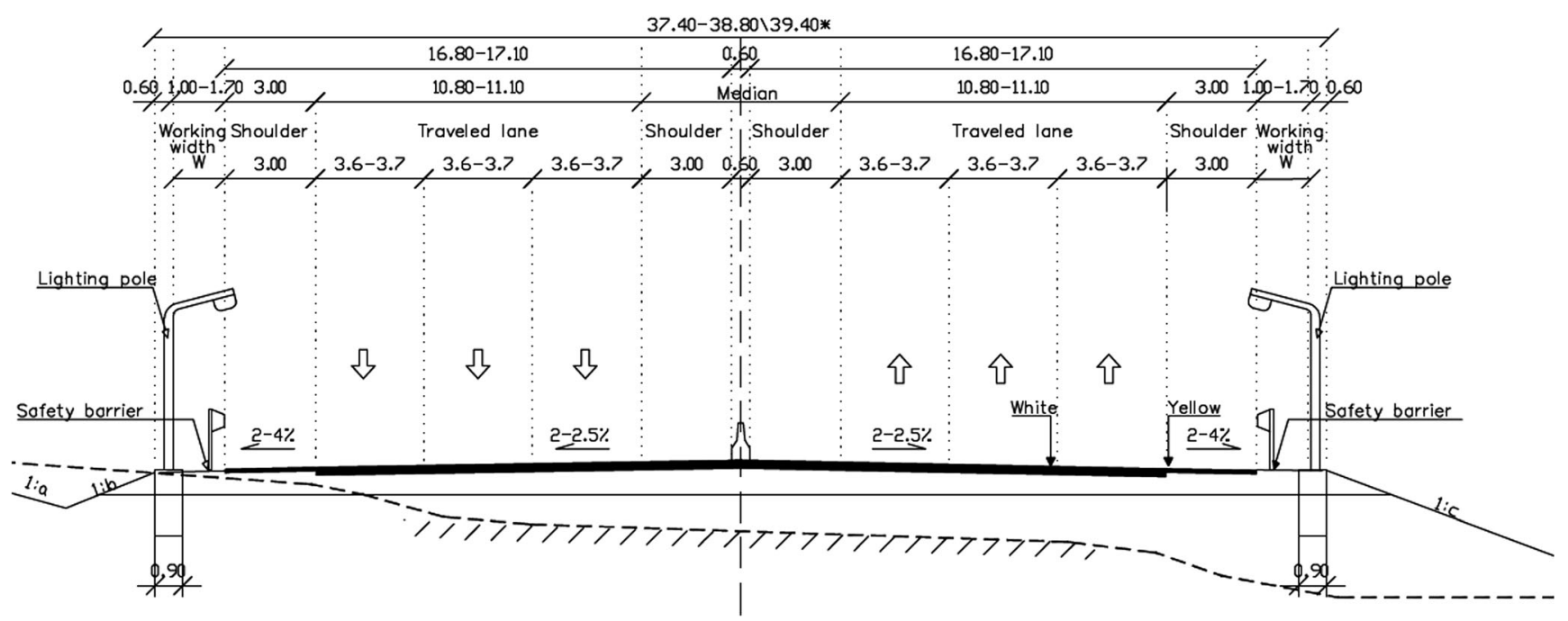

Fig. 5 Typical cross section of 6 lanes divided highway: freeway, major highway, minor highway with lighting pole aside (based on ISRAEL highway design guidelines [18])

\subsection{Sensitivity analysis for available horizontal sight distance and desirable radii (SSD $>$ L), case 2}

The gap between the available horizontal SSD (for $\mathrm{R}=\mathrm{Rmin}$ ) vs. the design $\mathrm{SSD}$ values and between Rmin (equilibrium concept) and the desirable radius (based on SSD design values) can be reduced when SSD $>$ L (Eq. 10, 10a).

Table 4 presents examples of SSD restrictions on a horizontal curve when $\mathrm{SSD}=2 \cdot \mathrm{L}$.

Table 4 notifies that if SSD $=2 \cdot \mathrm{L}$, the gap is reduced but is still maintained i.e.:

$$
\mathrm{AB}_{\text {Available }}<\mathrm{SSD} \text {, and, } \mathrm{R}_{\text {Desirable }}>\mathrm{R}_{\text {min }} \text {. }
$$

By conducting sensitivity analysis for SSD $>$ L we can obtain the ratio between SSD and L that will totally diminish this gap and reach an optimal or desirable situation when sight distance requirements are accomplished for horizontal curves design. Mathematically the criteria for resolving this gap for whole range of design speeds are:

$\mathrm{AB}_{\text {Available }} \geq \mathrm{SSD}$, and, $\mathrm{R}_{\text {Desirable }} \leq \mathrm{R}_{\text {min }}$.

Even if this gap is totally resolved the question is how practical is the ratio between SSD and L that is obtained for this optimal situation.

Table 5 and Table 6 present the results of sensitivity analysis for $\mathrm{AB}_{\text {Availabe }}$ when $\mathrm{HSO}=4.8 \mathrm{~m}$ and $\mathrm{HSO}=3.0 \mathrm{~m}$

Table 3 Examples of SSD restrictions on horizontal curves, based on AASHTO SSD design values (SSD $\leq$ L), Case 1

\begin{tabular}{|c|c|c|c|c|c|c|c|}
\hline \multirow[t]{2}{*}{ SSD restrictions } & \multicolumn{7}{|c|}{ Design speed, $\mathrm{V}_{\mathrm{d}}(\mathrm{km} / \mathrm{h})$} \\
\hline & 60 & 70 & 80 & 90 & 100 & 110 & 120 \\
\hline Stopping sight distance, SSD (m), AASHTO [2] & 85 & 105 & 130 & 160 & 185 & 220 & 250 \\
\hline Calculated radius $(\mathrm{m})$ : desirable $(\mathrm{HSO}=4.8 \mathrm{~m})^{*}$ & 188 & 287 & 440 & 667 & 891 & 1260 & 1628 \\
\hline Calculated radius $(\mathrm{m}):$ desirable $(\mathrm{HSO}=3.0 \mathrm{~m}){ }^{*}$ & 301 & 459 & 704 & 1067 & 1426 & 2017 & 2604 \\
\hline Minimum radius, $\mathrm{Rmin}(\mathrm{m})$, equilibrium concept $\mathrm{e}(\max )=8 \%$, [2] & 113 & 168 & 229 & 304 & 394 & 501 & 667 \\
\hline AB: Available SSD (m), HSO $=4.8 \mathrm{~m}, \mathrm{R}=\mathrm{Rmin} * *$ & 66 & 80 & 94 & 108 & 123 & 139 & 160 \\
\hline AB: Available SSD (m), HSO $=3.0 \mathrm{~m}, \mathrm{R}=\mathrm{Rmin} * *$ & 52 & 63 & 74 & 85 & 97 & 110 & 127 \\
\hline
\end{tabular}

Clarifications:

SSD (m): demanded stopping sight distance based on Eq. 1. Its design values are adopted from AASHTO [2].

Calculated radius-desirable (m): horizontal radius derived by horizontal sightline offset (HSO) and SSD according to Eq. 6.

Minimum radius (Rmin), (m): minimum horizontal radius derived from equilibrium concept (Eq. 2). Its design values are adopted from AASHTO [2].

AB (m): Available SSD derived by the minimum radius (Rmin) and $\mathrm{HSO}$, according to Eq. 6 a.

* Calculated radius for desirable SSD: $\mathrm{R}$ (desirable) $=\mathrm{SSD}^{2} /(8 \cdot \mathrm{HSO})$, for $\mathrm{SSD} \leq \mathrm{L}$, based on Eq. 6

$* *$ Calculated $\mathrm{AB}$ for Rmin: $A B_{\text {Available }}=\sqrt{H S O \cdot 8 \cdot R_{\min }}$, for $\mathrm{SSD} \leq \mathrm{L}$, based on Eq. $6 \mathrm{a}$ 


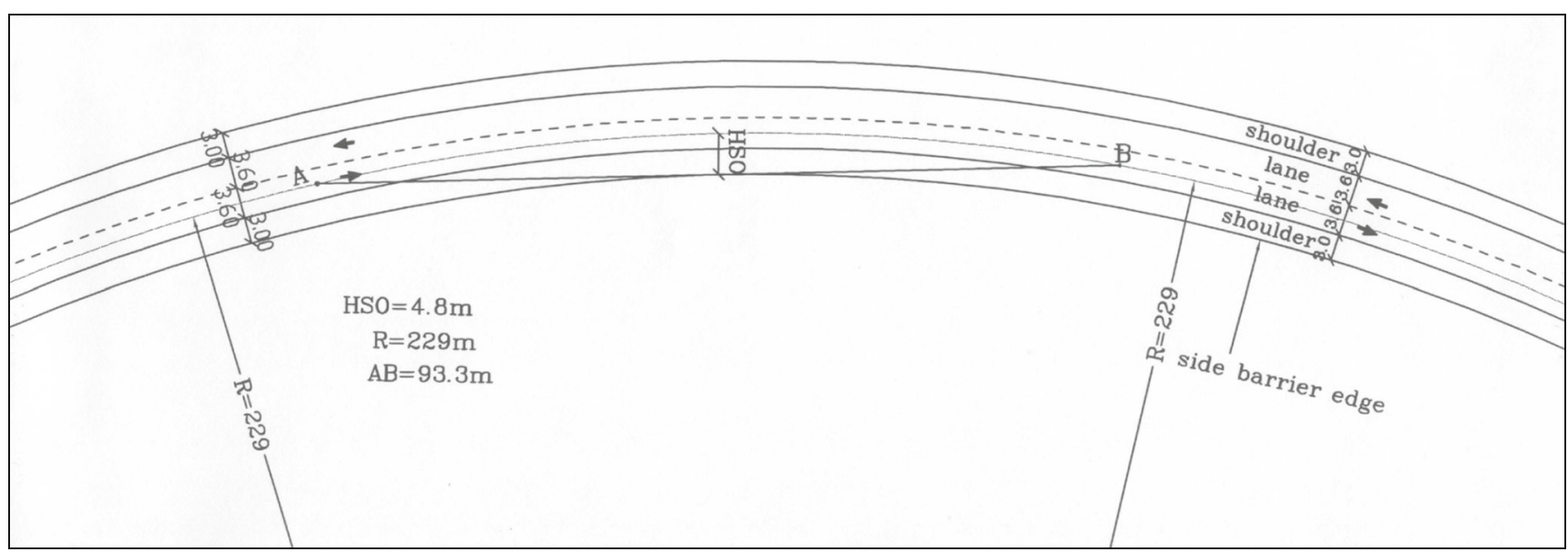

Fig. 6 Example of a Restricted SSD Line for a Two-Lane Highway $\left(V_{d}=80 \mathrm{~km} / \mathrm{h}\right), \mathrm{SSD} \leq \mathrm{L}$

correspondingly. Table 7 and Table 8 present the results of sensitivity analysis for $\mathrm{R}_{\text {Desirable }}$ when $\mathrm{HSO}=4.8 \mathrm{~m}$ and $\mathrm{HSO}=3.0 \mathrm{~m}$ correspondingly. Each table is followed by a graphical presentation of its sensitivity analysis results (Figs. 8, 9, 10 and 11 respectively).

The sensitivity analysis results for SSD $>$ L (Case 2) show that the gap between the available horizontal SSD (for $\mathrm{R}=\mathrm{Rmin}$ ) vs. the design $\mathrm{SSD}$ values and between Rmin (equilibrium concept) vs. the desirable radius can be totally resolved under the following conditions:

- $\quad$ For $\mathrm{HSO}=4.8 \mathrm{~m}$ the ratio between $\mathrm{SSD}$ and $\mathrm{L}$ is 4.5 .

- For $\mathrm{HSO}=3.0 \mathrm{~m}$ (more limited horizontal sight distance) the ratio between $\mathrm{SSD}$ and $\mathrm{L}$ is 7.5.

The critical design speed for meeting the horizontal sight distance criteria is approximately $110 \mathrm{~km} / \mathrm{h}$.

It appears that practically such conditions are not feasible for design especially for $\mathrm{HSO}=3.0 \mathrm{~m}$. The resulted length values of the two additional tangent edges (1) of the stopping sight distance beyond the horizontal curve L (1 in Fig. 3) are as follows:

- $\quad$ For HSO $=4.8 \mathrm{~m}, 1=(\mathrm{SSD}-\mathrm{L}) / 2=(4.5 \cdot \mathrm{L}-\mathrm{L}) / 2=1.75 \cdot \mathrm{L}$

- $\quad$ For HSO $=3.0 \mathrm{~m}, 1=(\mathrm{SSD}-\mathrm{L}) / 2=(7.5 \cdot \mathrm{L}-\mathrm{L}) / 2=3.75 \cdot \mathrm{L}$

These resulted lengths of tangent edges, especially for $\mathrm{HSO}=3.0 \mathrm{~m}$, are much longer than the horizontal curve $(\mathrm{L})$ itself.

This means that the highway engineer might consider increasing the horizontal curve radius as well as implementing limited dimensions of tangent edges (l). If the designed radius of the horizontal curve is larger than the minimum radius determined by Eq. 2, then the horizontal curve can be designed to a smaller superelevation rate than the maximum superelevation, $\mathrm{e}_{\max }$, and maintain less constrained and more comfort driving in addition to the basic advantage of less limited horizontal sight distance discussed in this study.

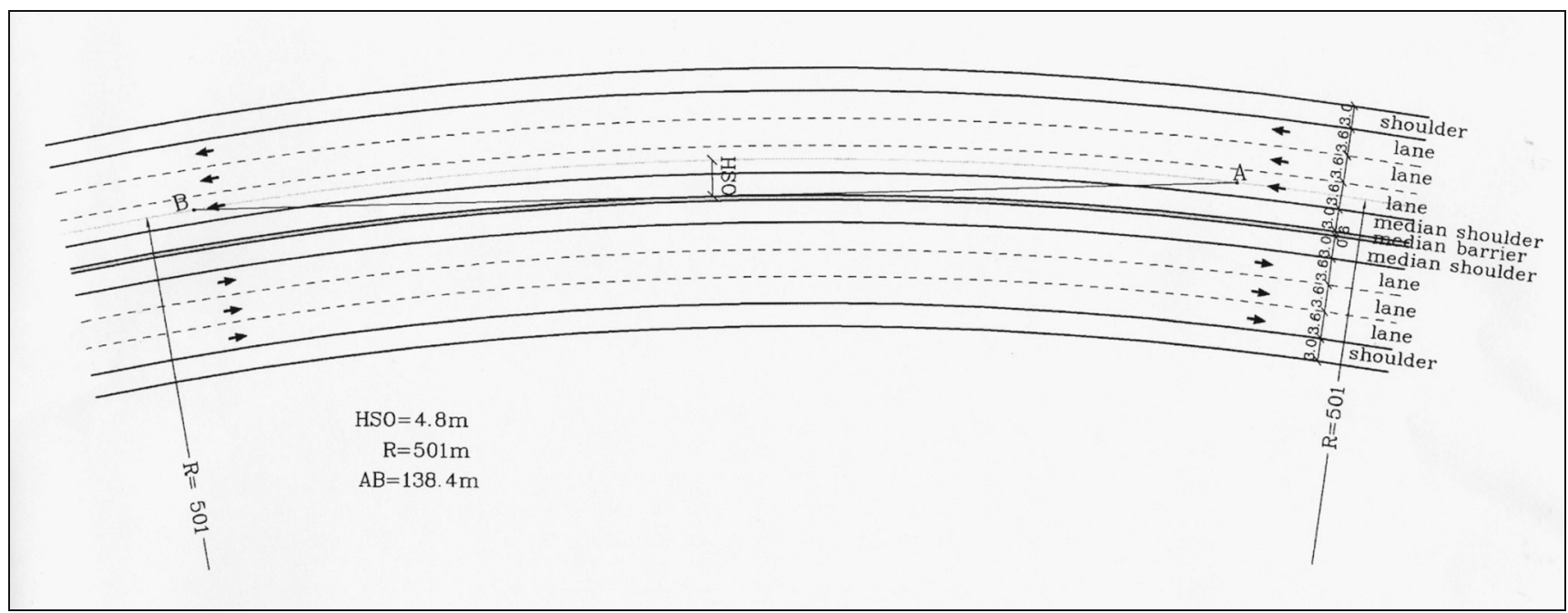

Fig. 7 Example of a Restricted SSD Line for a Six-lane Divided Highway $\left(\mathrm{V}_{\mathrm{d}}=110 \mathrm{~km} / \mathrm{h}\right), \mathrm{SSD} \leq \mathrm{L}$ 
Table 4 Examples of SSD restrictions on horizontal curves, based on AASHTO SSD design values (SSD = 2·L), Case 2

\begin{tabular}{|c|c|c|c|c|c|c|c|}
\hline \multirow[t]{2}{*}{ SSD restrictions } & \multicolumn{7}{|c|}{ Design speed, $\mathrm{V}_{\mathrm{d}}(\mathrm{km} / \mathrm{h})$} \\
\hline & 60 & 70 & 80 & 90 & 100 & 110 & 120 \\
\hline Stopping sight distance, SSD (m), AASHTO [2] & 85 & 105 & 130 & 160 & 185 & 220 & 250 \\
\hline Calculated radius $(\mathrm{m})$ : desirable $(\mathrm{HSO}=4.8 \mathrm{~m})^{*}$ & 141 & 215 & 330 & 500 & 668 & 945 & 1221 \\
\hline Calculated radius $(\mathrm{m})$ : desirable $(\mathrm{HSO}=3.0 \mathrm{~m}) *$ & 226 & 345 & 528 & 800 & 1070 & 1513 & 1953 \\
\hline Minimum radius, $\mathrm{Rmin}(\mathrm{m})$, equilibrium concept, $\mathrm{e}(\max )=8 \%$, [2] & 113 & 168 & 229 & 304 & 394 & 501 & 667 \\
\hline $\mathrm{AB}$ Available SSD $(\mathrm{m}) \mathrm{HSO}=4.8 \mathrm{~m}, \mathrm{R}=\mathrm{Rmin} * *$ & 72 & 88 & 100 & 113 & 128 & 142 & 165 \\
\hline $\mathrm{AB}$ Available SSD $(\mathrm{m}) \mathrm{HSO}=3.0 \mathrm{~m}, \mathrm{R}=\mathrm{Rmin} * *$ & 53 & 65 & 75 & 86 & 97 & 110 & 127 \\
\hline
\end{tabular}

Clarifications:

See clarifications of Table 3 for SSD and Rmin.

Calculated radius-desirable (m): horizontal radius derived by horizontal sightline offset (HSO) and SSD according to Eq. 10.

AB (m): Available SSD derived by the minimum radius (Rmin) and HSO, according to Eq. 10a.

*Calculated desirable radius for SSD: $R_{\text {Desirable }}=\frac{L \cdot(2 \cdot S S D-L)}{8 \cdot H S O}$, for $\mathrm{SSD}>\mathrm{L}$, based on Eq. 10

$* *$ Calculated $\mathrm{AB}$ for Rmin: $A B_{\text {Available }}=\frac{(H S O) \cdot 4 \cdot R_{\min }}{L}+\frac{L}{2}$, for $\mathrm{SSD}>\mathrm{L}$, based on Eq. 10a

\section{Summary and conclusion}

Barriers along open highways and walls on tunnels may restrict the available sight distance in the design of horizontal curves. The minimum radius that is based on the equilibrium of the centrifugal force, is too small for the requirements of stopping sight distance when there are obstructions along the road (especially the median barrier

Table 5 Sensitivity analysis of $\mathrm{AB}_{\text {Available }}$ (Available horizontal sight distance), $\mathrm{HSO}=4.8 \mathrm{~m}, \mathrm{SSD}>\mathrm{L}$, Case 2

\begin{tabular}{|c|c|c|c|c|c|c|c|}
\hline Design speed $(\mathrm{km} / \mathrm{h})$ & 60 & 70 & 80 & 90 & 100 & 110 & 120 \\
\hline Stopping sight distance (m) & 85 & 105 & 130 & 160 & 185 & 220 & 250 \\
\hline \multicolumn{8}{|l|}{$\mathrm{AB}(\mathrm{HSO}=4.8), \mathrm{R}=\mathrm{Rmin}$} \\
\hline $\mathrm{S}=1.0 \cdot \mathrm{L}$ & 66 & 80 & 94 & 108 & 123 & 139 & 160 \\
\hline $\mathrm{S}=1.5 \cdot \mathrm{L}$ & 67 & 81 & 94 & 108 & 123 & 139 & 160 \\
\hline $\mathrm{S}=2.0 \cdot \mathrm{L}$ & 72 & 88 & 100 & 113 & 128 & 142 & 165 \\
\hline $\mathrm{S}=2.5 \cdot \mathrm{L}$ & 81 & 98 & 111 & 123 & 139 & 153 & 178 \\
\hline $\mathrm{S}=3.0 \cdot \mathrm{L}$ & 91 & 110 & 123 & 136 & 154 & 168 & 195 \\
\hline $\mathrm{S}=3.5 \cdot \mathrm{L}$ & 101 & 123 & 137 & 151 & 170 & 184 & 215 \\
\hline $\mathrm{S}=3.75 \cdot \mathrm{L}$ & 107 & 129 & 144 & 158 & 178 & 193 & 225 \\
\hline $\mathrm{S}=4.0 \cdot \mathrm{L}$ & 113 & 136 & 152 & 166 & 187 & 202 & 236 \\
\hline $\mathrm{S}=4.25 \cdot \mathrm{L}$ & 118 & 143 & 159 & 174 & 196 & 212 & 247 \\
\hline $\mathrm{S}=4.5 \cdot \mathrm{L}$ & 124 & 150 & 167 & 182 & 205 & 221 & 258 \\
\hline $\mathrm{S}=4.75 \cdot \mathrm{L}$ & 130 & 157 & 174 & 190 & 214 & 231 & 270 \\
\hline $\mathrm{S}=5.0 \cdot \mathrm{L}$ & 136 & 164 & 182 & 198 & 223 & 241 & 281 \\
\hline $\mathrm{S}=6.0 \cdot \mathrm{L}$ & 160 & 193 & 214 & 232 & 261 & 281 & 328 \\
\hline $\mathrm{S}=7.0 \cdot \mathrm{L}$ & 185 & 223 & 246 & 267 & 299 & 322 & 376 \\
\hline $\mathrm{S}=7.5 \cdot \mathrm{L}$ & 197 & 237 & 262 & 284 & 319 & 343 & 401 \\
\hline Horizontal Rmin for emax $=8 \%$ & 113 & 168 & 229 & 304 & 394 & 501 & 667 \\
\hline
\end{tabular}

The bold row signifies the critical ratio $(\mathrm{S} / \mathrm{L})$ where $\mathrm{AB}_{\text {Available }} \geq \mathrm{SSD}$ for all design speeds on open roadways) that intrude on the line of sight. This study focuses on sight distance restrictions on horizontal curves.

The study examines these restrictions for the conventional case (case 1) when the stopping sight distance lies within the length of the horizontal curve (i.e. SSD $\leq \mathrm{L}$ ) and for the second scenario (case 2) when the sight distance lies outside the length of the horizontal curve (i.e. SSD $>$ L).

Table 6 Sensitivity analysis of $\mathrm{AB}_{\text {Available }}$ (Available horizontal sight distance), $\mathrm{HSO}=3.0 \mathrm{~m}, \mathrm{SSD}>\mathrm{L}$, Case 2

\begin{tabular}{|c|c|c|c|c|c|c|c|}
\hline Design speed (km/h) & 60 & 70 & 80 & 90 & 100 & 110 & 120 \\
\hline Stopping sight distance (m) & 85 & 105 & 130 & 160 & 185 & 220 & 250 \\
\hline \multicolumn{8}{|l|}{$\mathrm{AB}(\mathrm{HSO}=3.0), \mathrm{R}=\mathrm{Rmin}$} \\
\hline $\mathrm{S}=1.0 \cdot \mathrm{L}$ & 52 & 63 & 74 & 85 & 97 & 110 & 127 \\
\hline $\mathrm{S}=1.5 \cdot \mathrm{L}$ & 52 & 64 & 75 & 88 & 100 & 114 & 131 \\
\hline $\mathrm{S}=2.0 \cdot \mathrm{L}$ & 53 & 65 & 75 & 86 & 97 & 110 & 127 \\
\hline $\mathrm{S}=2.5 \cdot \mathrm{L}$ & 57 & 69 & 79 & 89 & 101 & 112 & 130 \\
\hline $\mathrm{S}=3.0 \cdot \mathrm{L}$ & 62 & 75 & 85 & 95 & 108 & 119 & 138 \\
\hline $\mathrm{S}=3.5 \cdot \mathrm{L}$ & 68 & 82 & 93 & 103 & 116 & 127 & 148 \\
\hline $\mathrm{S}=3.75 \cdot \mathrm{L}$ & 71 & 86 & 97 & 107 & 121 & 132 & 153 \\
\hline $\mathrm{S}=4.0 \cdot \mathrm{L}$ & 74 & 90 & 101 & 111 & 125 & 137 & 159 \\
\hline $\mathrm{S}=4.25 \cdot \mathrm{L}$ & 78 & 94 & 105 & 116 & 130 & 142 & 165 \\
\hline $\mathrm{S}=4.5 \cdot \mathrm{L}$ & 81 & 98 & 110 & 120 & 136 & 147 & 172 \\
\hline $\mathrm{S}=4.75 \cdot \mathrm{L}$ & 85 & 102 & 114 & 125 & 141 & 153 & 178 \\
\hline $\mathrm{S}=5.0 \cdot \mathrm{L}$ & 88 & 107 & 119 & 130 & 146 & 159 & 185 \\
\hline $\mathrm{S}=6.0 \cdot \mathrm{L}$ & 103 & 124 & 138 & 150 & 169 & 182 & 213 \\
\hline $\mathrm{S}=7.0 \cdot \mathrm{L}$ & 118 & 142 & 157 & 171 & 192 & 207 & 242 \\
\hline $\mathrm{S}=7.5 \cdot \mathrm{L}$ & 125 & 151 & 167 & 182 & 204 & 220 & 257 \\
\hline
\end{tabular}

Horizontal Rmin for emax $=8 \% \begin{array}{llllllll}113 & 168 & 229 & 304 & 394 & 501 & 667\end{array}$

The bold row signifies the critical ratio $(\mathrm{S} / \mathrm{L})$ where $\mathrm{AB}_{\text {Available }} \geq \mathrm{SSD}$ for all design speeds 
Table 7 Sensitivity analysis of $\mathrm{R}_{\text {Desirable }}, \mathrm{HSO}=4.8 \mathrm{~m}, \mathrm{SSD}>\mathrm{L}$, Case 2

When $\mathrm{SSD} \leq \mathrm{L}$ the differences between the available horizontal SSD (for $\mathrm{R}=\mathrm{Rmin}$ ) vs. the design (demanded) SSD values and between Rmin (equilibrium concept) vs. the desirable horizontal radius (based on SSD design values) are significant.

\begin{tabular}{lrrrrrrr}
\hline Design speed $(\mathrm{km} / \mathrm{h})$ & 60 & 70 & 80 & 90 & 100 & 110 & 120 \\
\hline Stopping sight distance $(\mathrm{m})$ & 85 & 105 & 130 & 160 & 185 & 220 & 250 \\
$\mathrm{R}_{\mathrm{SSD}}(\mathrm{HSO}=4.8)$ & & & & & & & \\
$\quad \mathrm{S}=1.0 \cdot \mathrm{L}$ & 188 & 287 & 440 & 667 & 891 & 1260 & 1628 \\
$\mathrm{~S}=1.5 \cdot \mathrm{L}$ & 167 & 255 & 391 & 593 & 792 & 1120 & 1447 \\
$\mathrm{~S}=2.0 \cdot \mathrm{L}$ & 141 & 215 & 330 & 500 & 668 & 945 & 1221 \\
$\mathrm{~S}=2.5 \cdot \mathrm{L}$ & 120 & 184 & 282 & 427 & 570 & 807 & 1042 \\
$\mathrm{~S}=3.0 \cdot \mathrm{L}$ & 105 & 160 & 245 & 370 & 495 & 700 & 904 \\
$\mathrm{~S}=3.5 \cdot \mathrm{L}$ & 92 & 141 & 216 & 327 & 437 & 617 & 797 \\
$\mathrm{~S}=3.75 \cdot \mathrm{L}$ & 87 & 133 & 203 & 308 & 412 & 583 & 752 \\
$\mathrm{~S}=4.0 \cdot \mathrm{L}$ & 82 & 126 & 193 & 292 & 390 & 551 & 712 \\
$\mathrm{~S}=4.25 \cdot \mathrm{L}$ & 78 & 119 & 183 & 277 & 370 & 523 & 676 \\
$\mathrm{~S}=\mathbf{4 . 5} \cdot \mathrm{L}$ & $\mathbf{7 4}$ & $\mathbf{1 1 3}$ & $\mathbf{1 7 4}$ & $\mathbf{2 6 3}$ & $\mathbf{3 5 2}$ & $\mathbf{4 9 8}$ & $\mathbf{6 4 3}$ \\
$\mathrm{S}=4.75 \cdot \mathrm{L}$ & 71 & 108 & 166 & 251 & 336 & 475 & 613 \\
$\mathrm{~S}=5.0 \cdot \mathrm{L}$ & 68 & 103 & 158 & 240 & 321 & 454 & 586 \\
$\mathrm{~S}=6.0 \cdot \mathrm{L}$ & 57 & 88 & 134 & 204 & 272 & 385 & 497 \\
$\mathrm{~S}=7.0 \cdot \mathrm{L}$ & 50 & 76 & 117 & 177 & 236 & 334 & 432 \\
$\mathrm{~S}=7.5 \cdot \mathrm{L}$ & 47 & 71 & 110 & 166 & 222 & 314 & 405 \\
Horizontal Rmin for emax $=8 \%$ & 113 & 168 & 229 & 304 & 394 & 501 & 667 \\
\hline
\end{tabular}

The bold row signifies the critical ratio $(S / L)$ where $R_{\text {Desirable }} \leq R_{\min }$ for all design speeds
Table 8 Sensitivity analysis of $\mathrm{R}_{\text {Desirable }}, \mathrm{HSO}=3.0 \mathrm{~m}$, $\mathrm{SSD}>\mathrm{L}$, Case 2
The sensitivity analysis results for SSD $>$ L show that the gap between the available horizontal SSD (for $\mathrm{R}=\mathrm{Rmin}$ ) vs. the design SSD values and between Rmin vs. the desirable radius can be totally resolved when $\mathrm{SSD} / \mathrm{L}$ equals to 4.5 for $\mathrm{HSO}=4.8 \mathrm{~m}$, and when $\mathrm{SSD} / \mathrm{L}$ equals to 7.5 (for

\begin{tabular}{lrrrrrrr}
\hline Design speed $(\mathrm{km} / \mathrm{h})$ & 60 & 70 & 80 & 90 & 100 & 110 & 120 \\
\hline Stopping sight distance $(\mathrm{m})$ & 85 & 105 & 130 & 160 & 185 & 220 & 250 \\
$\mathrm{R}_{\mathrm{SSD}}(\mathrm{HSO}=3.0)$ & & & & & & & \\
$\mathrm{S}=1.0 \cdot \mathrm{L}$ & 301 & 459 & 704 & 1067 & 1426 & 2017 & 2604 \\
$\mathrm{~S}=1.5 \cdot \mathrm{L}$ & 268 & 408 & 626 & 948 & 1268 & 1793 & 2315 \\
$\mathrm{~S}=2.0 \cdot \mathrm{L}$ & 226 & 345 & 528 & 800 & 1070 & 1513 & 1953 \\
$\mathrm{~S}=2.5 \cdot \mathrm{L}$ & 193 & 294 & 451 & 683 & 913 & 1291 & 1667 \\
$\mathrm{~S}=3.0 \cdot \mathrm{L}$ & 167 & 255 & 391 & 593 & 792 & 1120 & 1447 \\
$\mathrm{~S}=3.5 \cdot \mathrm{L}$ & 147 & 225 & 345 & 522 & 698 & 988 & 1276 \\
$\mathrm{~S}=3.75 \cdot \mathrm{L}$ & 139 & 212 & 325 & 493 & 659 & 932 & 1204 \\
$\mathrm{~S}=4.0 \cdot \mathrm{L}$ & 132 & 201 & 308 & 467 & 624 & 882 & 1139 \\
$\mathrm{~S}=4.25 \cdot \mathrm{L}$ & 125 & 191 & 292 & 443 & 592 & 837 & 1081 \\
$\mathrm{~S}=4.5 \cdot \mathrm{L}$ & 119 & 181 & 278 & 421 & 563 & 797 & 1029 \\
$\mathrm{~S}=4.75 \cdot \mathrm{L}$ & 113 & 173 & 265 & 402 & 537 & 760 & 981 \\
$\mathrm{~S}=5.0 \cdot \mathrm{L}$ & 108 & 165 & 254 & 384 & 513 & 726 & 938 \\
$\mathrm{~S}=$ 6.0 $\mathrm{L}$ & 92 & 140 & 215 & 326 & 436 & 616 & 796 \\
$\mathrm{~S}=7.0 \cdot \mathrm{L}$ & 80 & 122 & 187 & 283 & 378 & 535 & 691 \\
$\mathrm{~S}=\mathbf{7 . 5} \cdot \mathrm{L}$ & $\mathbf{7 5}$ & $\mathbf{1 1 4}$ & $\mathbf{1 7 5}$ & $\mathbf{2 6 5}$ & $\mathbf{3 5 5}$ & $\mathbf{5 0 2}$ & $\mathbf{6 4 8}$ \\
$\mathrm{S}=8.0 \cdot \mathrm{L}$ & 71 & 108 & 165 & 250 & 334 & 473 & 610 \\
Horizontal Rmin for emax & 113 & 168 & 229 & 304 & 394 & 501 & 667 \\
\hline
\end{tabular}

The bold row signifies the critical ratio ( $/ \mathrm{L})$ where $\mathrm{R}_{\text {Desirable }} \leq \mathrm{R}_{\min }$ for all design speeds 


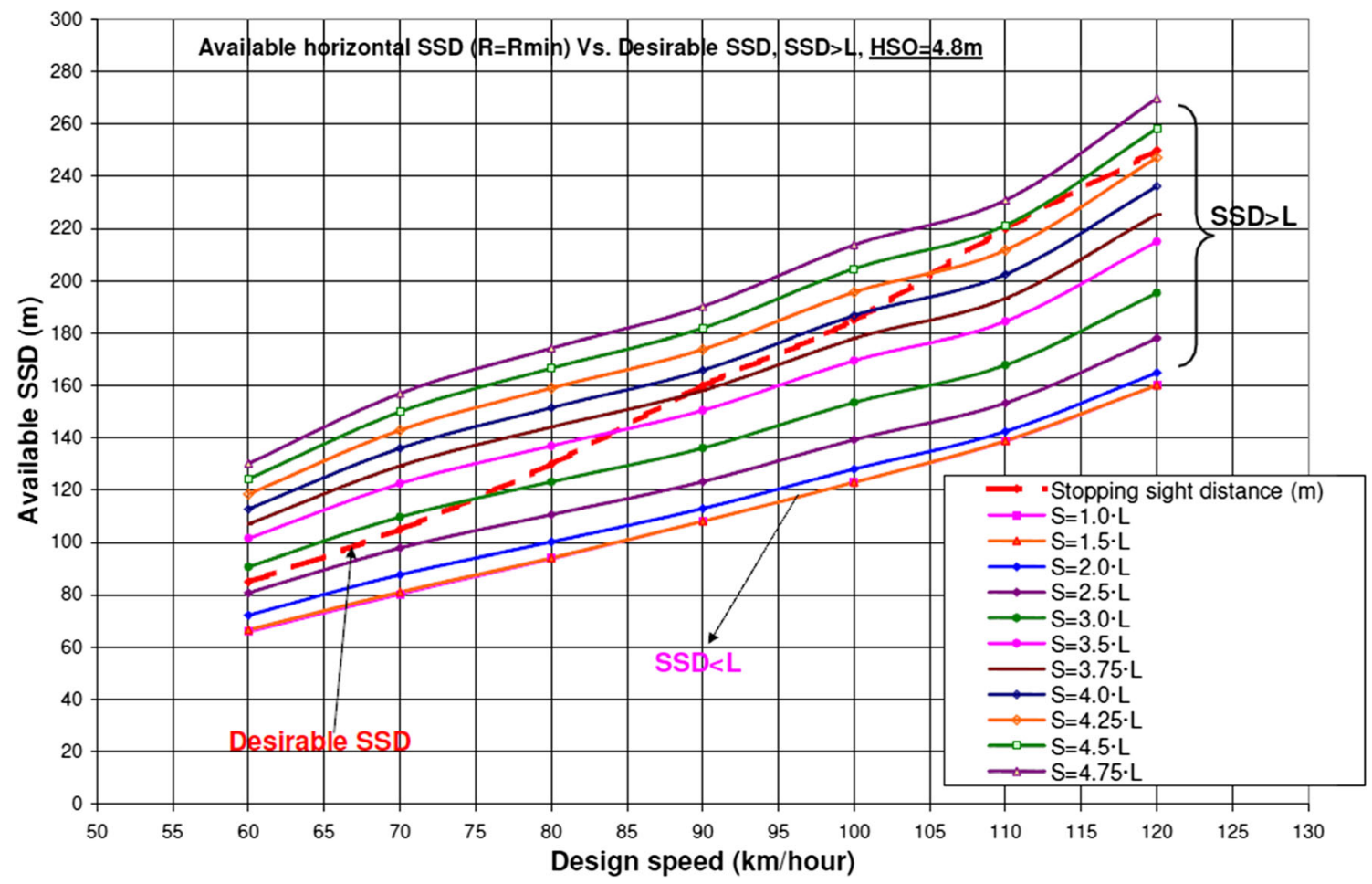

Fig. 8 Graphical presentation of the available horizontal sight distance $\left(\mathrm{AB}_{\text {Available}}\right), \mathrm{HSO}=4.8 \mathrm{~m}$, Vs. stopping sight distance $(\mathrm{SSD}>\mathrm{L})$

$\mathrm{HSO}=3.0 \mathrm{~m})$. Practically, in most cases, such conditions are not feasible in horizontal curve design, especially for $\mathrm{HSO}=3.0 \mathrm{~m}$.
The study also discusses the maximum obstruction height to ensure sightline while driving along a horizontal curve, for three types of sight distance (stopping SD, decision SD,

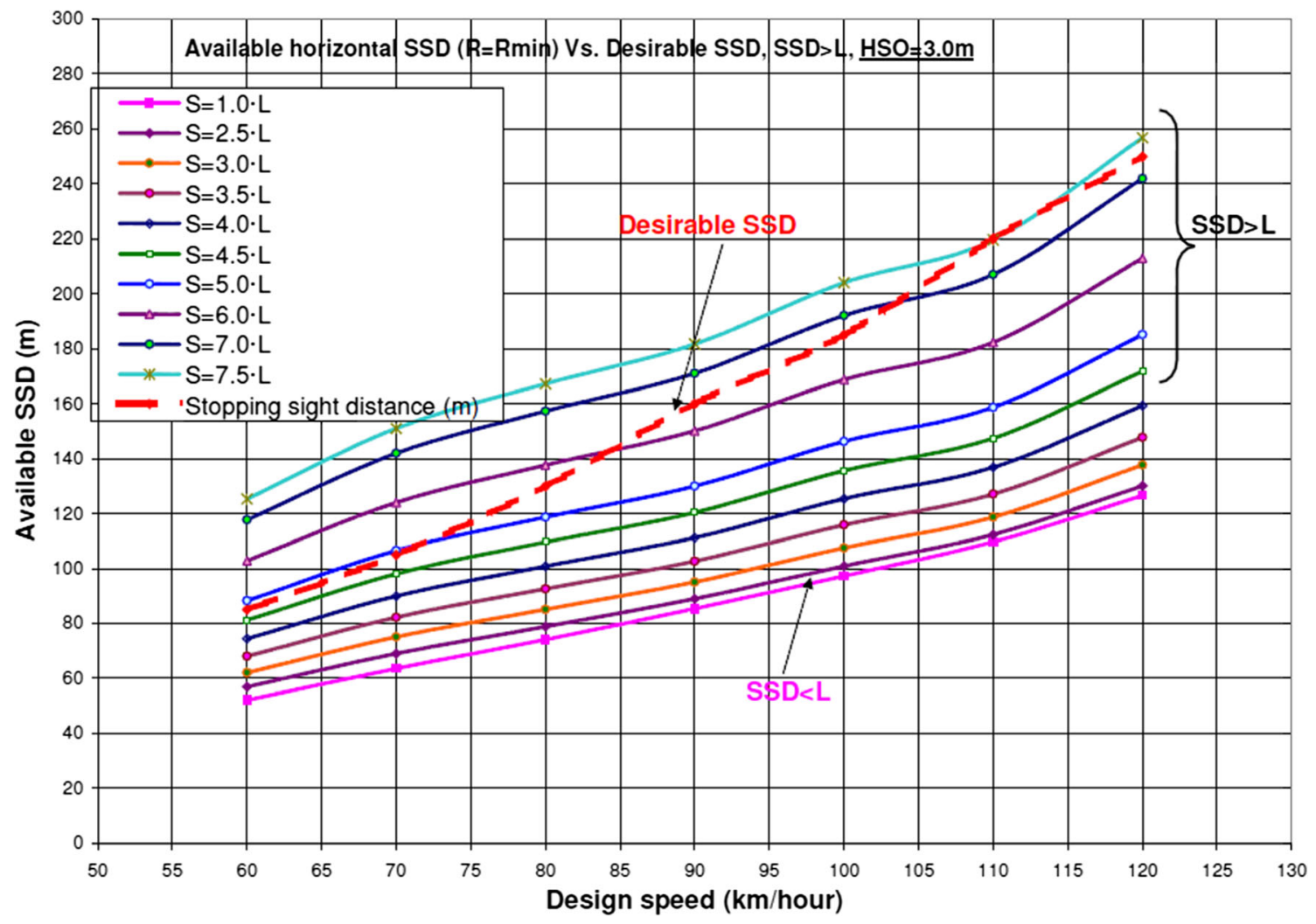

Fig. 9 Graphical presentation of the available horizontal sight distance $\left(\mathrm{AB}_{\text {Available }}\right), \mathrm{HSO}=3.0 \mathrm{~m}$, Vs. stopping sight distance $(\mathrm{SSD}>\mathrm{L})$ 


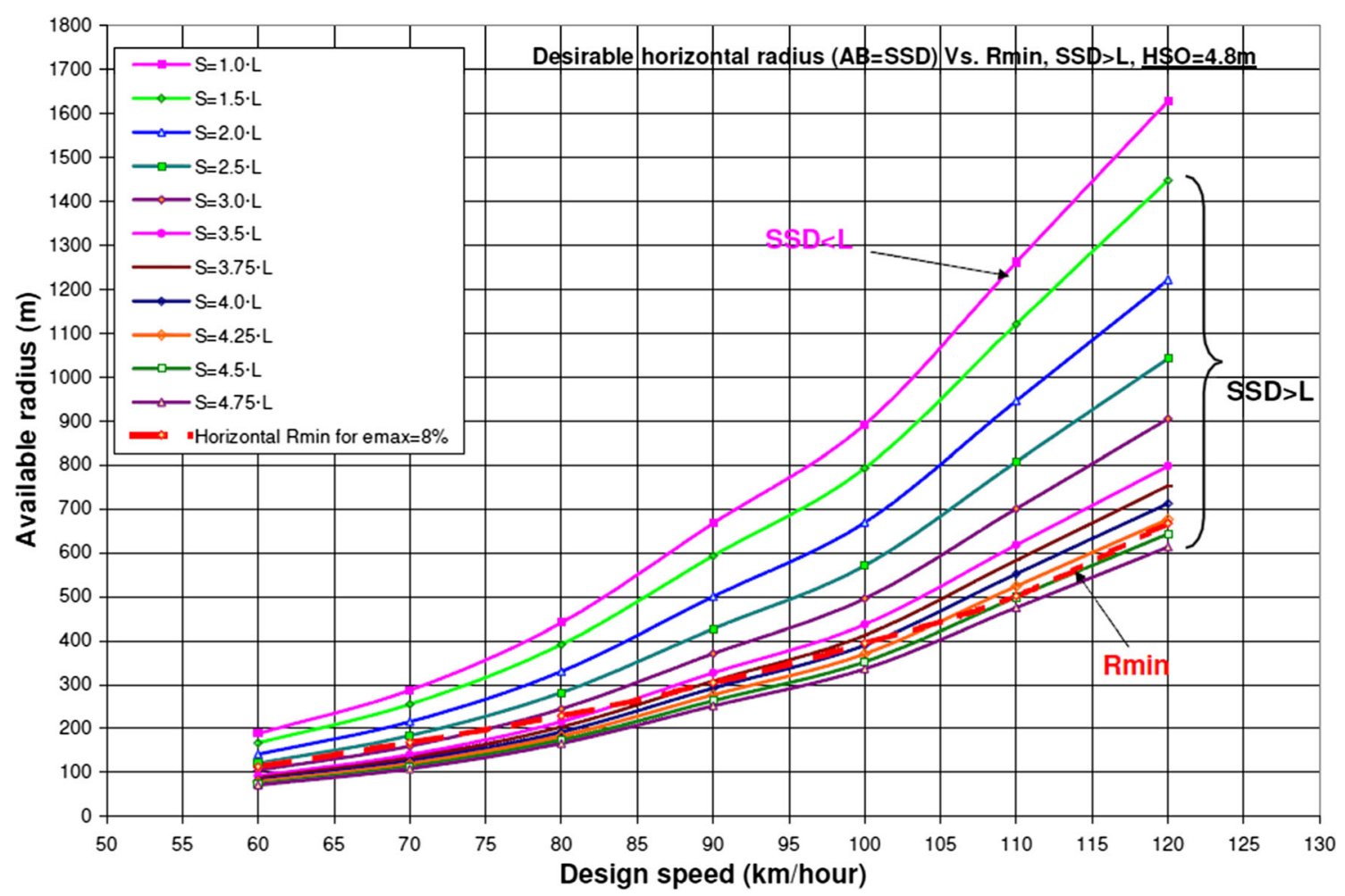

Fig. 10 Graphical presentation of $\mathrm{R}_{\text {Desirable }}, \mathrm{HSO}=4.8 \mathrm{~m}, \mathrm{Vs}$. Rmin $(\mathrm{SSD}>\mathrm{L})$

passing SD) when the horizontal sight distance requirements are not applicable. The maximum obstruction height is assumed to be the average between the driver eye height and the object height.
When the limitations of horizontal stopping sight distance are valid and the obstruction height is higher than its maximum value, the highway engineer might consider a tradeoff by increasing the horizontal curve radius as well as adjusting the design to

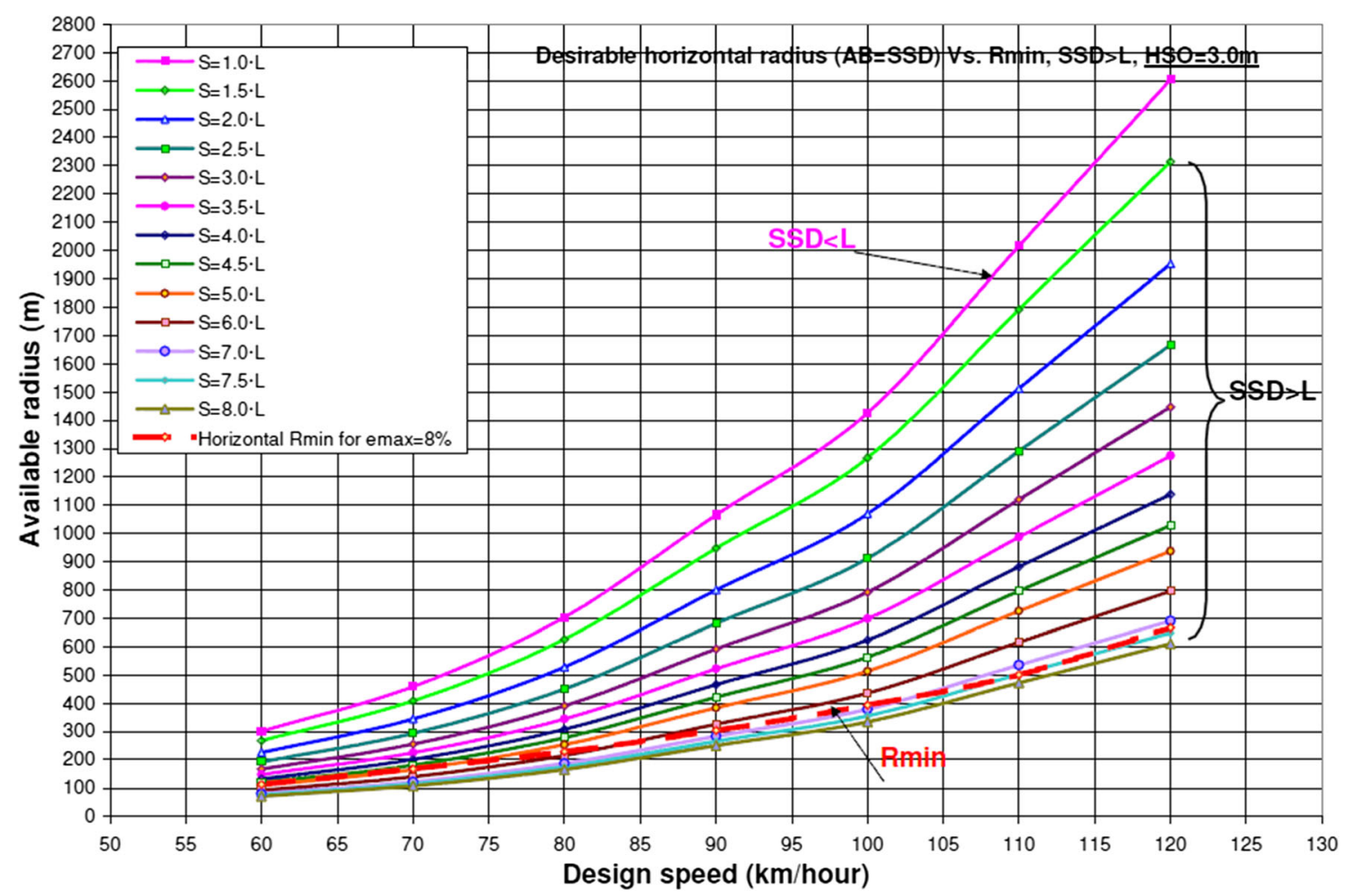

Fig. 11 Graphical presentation of $\mathrm{R}_{\text {Desirable, }}, \mathrm{HSO}=3.0 \mathrm{~m}, \mathrm{Vs}$. Rmin $(\mathrm{S}>\mathrm{L})$ 
$\mathrm{SSD}>\mathrm{L}$ and implementing limited dimensions of tangent edges (1). Additional improvements assuming that safety barriers intrude the sight distance could be: (1) reducing the design speed along the horizontal curve by no more than $10 \mathrm{~km} / \mathrm{h}$ (accompanied by appropriate traffic signs) in order to maintain design consistency, (2) widening the left shoulder or right shoulder along the horizontal curve in order to achieve wider HSO, (3) Using less conservative stopping sight distance criteria such as reducing the equivalent deceleration rate (d) if weather conditions are regularly dry or reducing the perception reaction time design value according to driving behavior characteristics $[3,19]$.

Open Access This article is distributed under the terms of the Creative Commons Attribution 4.0 International License (http:// creativecommons.org/licenses/by/4.0/), which permits unrestricted use, distribution, and reproduction in any medium, provided you give appropriate credit to the original author(s) and the source, provide a link to the Creative Commons license, and indicate if changes were made.

\section{References}

1. American Association of State Highway and Transportation Officials (AASHTO) (2011). A policy on geometric design of highways and streets, 6th Edition. Washington DC

2. American Association of State Highway and Transportation Officials (AASHTO) (2004). A policy on geometric design of highways and streets, 5th Edition. Washington DC

3. Arndt OK, Cox RL, Lennie SC, Whitehead MT (2011) Provision of sight distance around concrete barriers and structures on freeways and interchanges. Transp Res Rec 2262:22-30

4. Sarhan M, Hassan Y (2012) Consideration of sight distance in placement of concrete barriers on horizontal curves of roads. Transp Res Rec 1940:9-16

5. Mavromatis S., Psarianos B., Mertzanis F., Vardaki S (2015). Three dimensional stopping sight distance control on left turn curves of freeways overlapped with crest vertical curves. 5th International Symposium of Highway Geometric Design. Vancouver.6.2015.

6. Moreno CAT., Perez VMF, Garcia A, Romero RMA (2010). Optimal 3D coordination to maximize the available stopping sight distance in two-lane roads. 4th International Symposium of Highway Geometric Design. Valencia. Spain. 6.2010.

7. Hussein M, Sayed T, Ismail K, Van Espen A (2014) Calibrating road design guides using risk-based reliability analysis. J Transp Eng ASCE. 140(9):1-6

8. Guide to Road Design, Part 3: Geometric Design, AGRD03/09, Austroads, Sydney, NSW (Austroads 2009).

9. Nehate G, Rys M (2006) ). 3D calculation of stopping-sight distance from GPS data. J Transp Eng ASCE. 132(9):691-698

10. Kim DG, Lovell DJ (2010). A procedure for 3-D sight distance evaluation using thin plate splines. 4th International Symposium of Highway Geometric Design. Valencia. Spain. 6.2010

11. Castro M, Iglesias L, Sanchez JA, Ambrosio L (2011) Sight distance analysis of highways using GIS tools. Transportation Research C. 19(6):997-1005

12. Jha M, Karri G, Kuhn W (2011) New three-dimensional highway design methodology for sight distance measurement. Transp Res Rec Transportation Research Board of the National Academies. 2262:74-82

13. Mavromatis S, Palaskas S, Psarianos B (2012) Continuous threedimensional stopping sight distance control on crest vertical curves. Advances in Transportation Studies, an international Journal. Special Issue 2012. http://host.uniroma3.it/riviste/ats/

14. Ismail K, Sayed T (2007) New algorithm for calculating 3D available sight distance. J Transp Eng ASCE. 133(10):572-581

15. Ismail K, Sayed T (2012) Risk-optimal highway design: methodology and case studies. Saf Sci 50(7):1513-1521

16. Ibrahim SE, Sayed T, Ismail K (2012) "Methodology for safety optimization of highway cross-sections for horizontal curves with restricted sight distance.". Accident Analysis and Prevention 49: 476-485

17. Olson PL, Cleveland DE, Fancher PS, Schneider LW (1984) Parameters affecting stopping sight distance. Final Report. The University of Michigan. Transport Research Institute. UMTRI 8415. Ann Arbor, Michigan 48109. Prepared for: National Cooperative Highway Research Program. Transportation Research Board. National Research Council. http://mirlyn.lib. umich.edu/Record/004951575

18. Israel Interurban Highway Design Guidelines (2012) Published in Hebrew by Israel Ministry of Transportation and National Transport Infrastructure Company. http://media.mot.gov.il/PDF/HE_ TRAFFIC PLANNING/techen-geometry.pdf

19. Fambro DB, K Fitzpatrick, and RJ Koppa. (1997). NCHRP Report 400: Determination of Stopping Sight Distances TRB, National Research Council, Washington, DC 